\title{
Dynamic Characteristics Analysis and Experimental Verification of Long Span Suspension Bridge
}

\author{
Yang Guojun ${ }^{1,2}$, Tian Qiwei ${ }^{1}$, Tang Guangwu ${ }^{2}$, Li Longlong ${ }^{3}, \mathrm{Ye} \mathrm{Su}^{1}$ and Du Yongfeng ${ }^{1}$ \\ ${ }^{1}$ School of Civil Engineering, Lanzhou University of Technology, Lanzhou, 730050, China \\ ${ }^{2}$ State Key Laboratory of Bridge Engineering Structural Dynamic, China Merchants Chongqing Communications Technology Research \\ \& Design Institution CO., Ltd., Chongqing, 400067, China \\ ${ }^{3}$ Laboratory of Roadway Bridge \& Structure Engineering, Wuhan University of Technology, Wuhan, 430070, China
}

\begin{abstract}
The dynamic characteristics of long-span suspension bridges are complex. The natural vibration frequency is changed with different structural parameters, and the sensitivity to different parameters is different. In order to solve this problem, the spatial model of a long-span suspension bridge was established by using finite element software, and the first 20 natural vibration periods, natural vibration frequencies and vibration modes were analyzed and calculated. The accuracy of the obtained natural vibration frequency data was verified through field tests. Finally, based on the model, the stiffness of structural components is studied by one -factor-at-one-time, and the influence of various variables on the frequency and mode of a certain mode is studied by one-factor-at-one-time method. The results show that different structural parameters have different effects on the vibration frequency. When the stiffness of stiffening girder and main tower is changed, with the increase of stiffness, the variation of frequency mostly presents an upward trend, and the range is large. With the change of the secondary dead load, most of the frequencies decrease first and then tend to be stable. It can be seen from the field test results that the vibration shapes and frequencies measured by numerical simulation and test are close to each other, which can meet the requirements of engineering precision. The stiffness of the main cable and the main tower has a great influence on the modes and periods corresponding to them. The increase of the secondary dead load can reduce the natural vibration frequency of the suspension bridge, but it is not unlimited to increase the secondary dead load to reduce the frequency. The stiffness of the stiffening girder has a great influence on the frequency of the suspension bridge. When the bending stiffness of the stiffening girder increases to 3 times of the original one, the order of vibration modes of the structure will change. The research results can provide references for structural design and dynamic parameter adjustment of long-span suspension bridge.
\end{abstract}

\section{Introduction}

The dynamic characteristics of long-span suspension bridges are complex. When the structure is excited by external dynamics, the vibration modes in all directions in space can generally be divided into four types: horizontal, vertical, longitudinal, and torsion. Densely distributed to the vibration mode, the vibration frequency of the structure changes with the structure parameters and the sensitivity to the parameters is different [1]. The vibration frequency analysis method of suspension bridge can be divided into indoor test and theoretical analysis, which refers to installing multiple sensors on the suspension bridge, collecting relevant data, analyzing the modal frequency, damping ratio and vibration mode of the structure, and verifying them by approximate method, classical analysis method, empirical formula method and numerical method. From the perspective of bridge seismic and wind resistance design, the study of the dynamic characteristics of the long-span suspension bridges mainly need to solve two key issues. One is how to obtain the low-frequency dynamic characteristics of the real bridge, how to verify each other between the field tests and the numerical simulations; the other is how the structure parameters of the bridge affect the frequency and how to analyze the coupled vibration under environmental excitation.

Aiming at the first question, Xiang Yiqiang and others [2] gave an analytical formula for the analysis of the dynamic characteristics of the steel-concrete small box girder for rapid construction through theoretical derivation, and compared the theoretical value of the proposed method with the finite element analysis; on the basis of traditional parallel cable planes, Xia Jinlin and others [3] tried to reduce the lateral distance between two main cables to form a spatial cable system, and studied dynamic characteristics and flutter stability changes; Li Yongle and others [4] tested through wind tunnel tests and the three-component force coefficient of vehicles and bridges, and the use of self-developed software to compare and analyze the dynamic characteristics of the bridge and the wind - vehicle - bridge coupling vibration performance; Liu Jiabing [5] elaborated on the influence of different lengths of the train load on the internal force and deformation of the structure; Chen Yang and others [6] bases on the finite element simulation, the pulsation

※Corresponding author:yanggj403@163.com 
test was carried out and the natural vibration frequency, the vibration mode, and the dynamic strain impact coefficient and the dynamics of the main bridge analyzed; Xiao Haizhu [7] and others established finite element model of main bridge's overall space link system by using finite element method, and analyzed dynamic characteristics and influence of wind facilities on dynamic characteristics; using finite element software, Wang Hao and others [8] obtained the vibration mode and natural vibration frequency of the bridge, and analyzed the influence of important parameters such as the stiffness of the main girder on the dynamic characteristics of the bridge; Xu Shuo [9] and others used finite element software to analyze dynamic characteristics, and tested the kinetic parameters of the bridge structure through structural vibration test tests, and compared and analyzed the theoretical values. Regarding the second question, Wang Junwen and others [10] proposed the sensitivity analysis of the influencing parameters of the orthogonal test design for pre-stressed bridge piers; Xia Zhiyuan and others [11] studied the sensitivity parameters that affect the dynamic characteristics of suspension bridges, and discussed the effects of the concentration of dead load, ambient temperature and support settlement on the dynamic characteristics of the bridge; Tao and others [12] analyzed buffeting based on MTMD for a long-span three-tower suspension bridge sensitivity analysis of controlled parameters; Nazim and others [13] used a parameter analysis method based on Monte Carlo sampling to establish a numerical model and discussed the influence of different parameters on the aerodynamic stability of the structure.

To sum up, the existing research mainly uses theoretical derivation, numerical simulation and other methods to study the dynamic characteristics of bridge structures. However, there are few studies on the comparison of the dynamic characteristics obtained from the field test and numerical simulation of the long-span suspension bridge and the influence of the coupling of multiple parameters on the natural vibration period of the suspension bridge. Therefore, this paper takes a long span suspension bridge as a background project, the spatial model of a long-span suspension bridge was established by using finite element software, and the first 20 natural vibration periods, natural vibration frequencies and vibration modes were analyzed and calculated. The accuracy of the obtained natural vibration frequency data was verified through field tests. Finally, based on the model, the stiffness of structural components is studied and the influence of various variables on the frequency and mode of a certain mode is studied by one-factor-at-one-time method. Analyzing the parameters that affect the dynamic characteristics of long-span suspension bridges can provide convenience for the dynamic design of such structures.

\section{Numerical solution of natural vibration frequency}

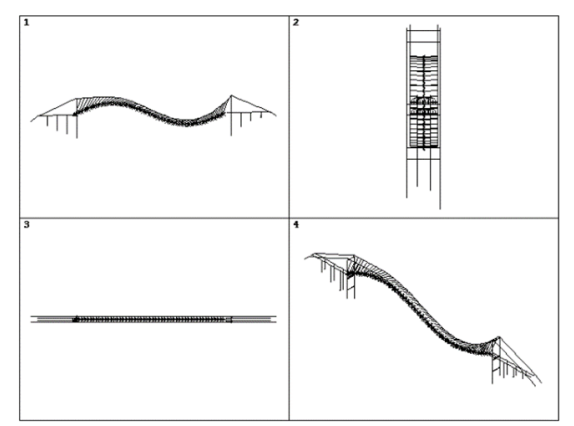

(c)1st ASVB MG $(0.1786 \mathrm{~Hz})$

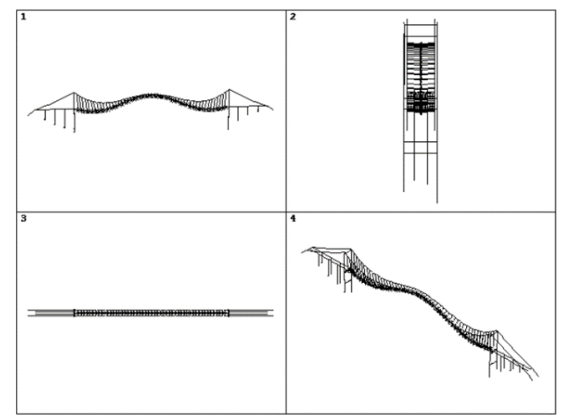

(d)1st SVB MG $(0.2243 \mathrm{~Hz})$

(b)1st STB MG（0.1338Hz）

Figure 1. The Partial Modal Shapes of the Bridge

Table 1 dynamic characteristics of the Background Bridge

\begin{tabular}{|c|c|c|c|c|c|c|c|}
\hline $\begin{array}{c}\text { Frequency } \\
\text { Order }\end{array}$ & $\begin{array}{c}\text { Frequency } \\
/ \mathrm{Hz}\end{array}$ & $\begin{array}{c}\text { Frequency } \\
/ \mathrm{s}\end{array}$ & $\begin{array}{l}\text { vibration mode } \\
\text { Characteristics }\end{array}$ & $\begin{array}{c}\text { Frequency } \\
\text { Order }\end{array}$ & $\begin{array}{c}\text { Frequency } \\
/ \mathrm{Hz}\end{array}$ & $\begin{array}{c}\text { Frequency } \\
/ \mathrm{s}\end{array}$ & $\begin{array}{l}\text { vibration mode } \\
\text { Characteristics }\end{array}$ \\
\hline 1 & 0.1261 & 7.9312 & $\begin{array}{c}\text { First-order longitudinal } \\
\text { drift of the main } \\
\text { girder(1st LD MG) }\end{array}$ & 11 & 0.4641 & 2.2551 & $\begin{array}{l}\text { Reverse bending of } \\
\text { main cable(RB MC) }\end{array}$ \\
\hline
\end{tabular}




\begin{tabular}{|c|c|c|c|c|c|c|c|}
\hline 2 & 0.1338 & 7.4748 & $\begin{array}{c}\text { First-order symmetrical } \\
\text { transverse bending of } \\
\text { main girder(1st STB } \\
\text { MG) }\end{array}$ & 12 & 0.4806 & 2.1548 & $\begin{array}{c}\text { First-order } \\
\text { symmetric torsion of } \\
\text { main girder(1st ST } \\
\text { MG) }\end{array}$ \\
\hline 3 & 0.1786 & 5.5982 & $\begin{array}{c}\text { First-order anti- } \\
\text { symmetric vertical } \\
\text { bending of the main } \\
\text { girder(1st ASVB MG) }\end{array}$ & 13 & 0.4824 & 2.0806 & $\begin{array}{l}\text { First-order anti- } \\
\text { symmetric torsion of } \\
\text { main girder(1st AST } \\
\text { MG) }\end{array}$ \\
\hline 4 & 0.2243 & 4.4586 & $\begin{array}{l}\text { First-order symmetric } \\
\text { vertical bending of } \\
\text { main girder(1st SVB } \\
\text { MG) }\end{array}$ & 14 & 0.5331 & 2.0728 & $\begin{array}{c}\text { First-order } \\
\text { symmetrical torsion } \\
\text { of main girder(1st } \\
\text { ST MG) }\end{array}$ \\
\hline 5 & 0.3015 & 3.3168 & $\begin{array}{c}\text { First-order symmetric } \\
\text { vertical vibration of } \\
\text { main girder(1st SVV } \\
\text { MG) }\end{array}$ & 15 & 0.5528 & 1.8758 & $\begin{array}{c}\text { Second-order } \\
\text { symmetric vertical } \\
\text { bending of main } \\
\text { girder(2nd SVB } \\
\text { MG) }\end{array}$ \\
\hline 6 & 0.3540 & 2.8247 & $\begin{array}{l}\text { First-order anti- } \\
\text { symmetric transverse } \\
\text { bending of main girder } \\
\text { and main cable(1st } \\
\text { ASTB MG\&MC) }\end{array}$ & 16 & 0.6447 & 1.8090 & $\begin{array}{c}\text { Syn-tropic bending } \\
\text { of main cable(SB } \\
\text { MC) }\end{array}$ \\
\hline 7 & 0.3928 & 2.5460 & $\begin{array}{l}\text { Synchronous anti- } \\
\text { symmetric transverse } \\
\text { bend of the main } \\
\text { cable(SASTB MC) }\end{array}$ & 17 & 0.6528 & 1.5512 & $\begin{array}{c}\text { Symmetrical } \\
\text { transverse syn-tropic } \\
\text { bending of the main } \\
\text { cable(STSB MC) }\end{array}$ \\
\hline 8 & 0.3955 & 2.5283 & $\begin{array}{l}\text { Second-order anti- } \\
\text { symmetric vertical } \\
\text { bending of the main } \\
\text { girder(2nd ASVB MG) }\end{array}$ & 18 & 0.6609 & 1.5319 & $\begin{array}{l}\text { Lateral vibration of } \\
\text { main cable(LB MC) }\end{array}$ \\
\hline 9 & 0.4066 & 2.4593 & $\begin{array}{l}\text { Anti-symmetric } \\
\text { bending of the main } \\
\text { cable(ASB MC) }\end{array}$ & 19 & 0.6669 & 1.5132 & $\begin{array}{l}\text { Syn-tropic vertical } \\
\text { bending of side-span } \\
\text { main cable(SVB } \\
\text { SMC) }\end{array}$ \\
\hline 10 & 0.4158 & 2.4051 & $\begin{array}{c}\text { Synthetic symmetric } \\
\text { transverse bending of } \\
\text { the main cable(SPSTB } \\
\text { MC) }\end{array}$ & 20 & 0.4641 & 1.4995 & $\begin{array}{l}\text { Reverse vertical } \\
\text { bending of side span- } \\
\text { main cable(RVB } \\
\text { SMC) }\end{array}$ \\
\hline
\end{tabular}

The structural dynamic characteristics of bridges mainly include: natural vibration periods, natural vibration frequencies and vibration modes. The finite element model is established on the background of a real bridge, and natural vibration period, natural vibration frequency and vibration mode can be directly calculated and analyzed in the finite element software. Table 1 lists the first 20 natural vibration periods, natural vibration frequencies and vibration modes of the background bridge, and Figure 1 shows part of the bridge vibration modes diagram.

\section{Field test verification of natural vibration frequency}

The previous part mainly used numerical simulation to theoretically analyze the dynamic characteristics of long-span suspension bridges. In order to verify the accuracy of the natural vibration frequency data obtained by numerical simulation, we verify it through the field dynamic load test, loading and data collection of field dynamic load test. The comparative analysis results of the actual measured value and the theoretical value of the part of the main bridge's dynamic characteristics are shown in Table 2 and Figure 2. 


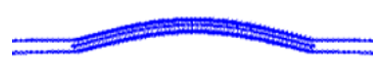

(a)1st STB MG (FEM)

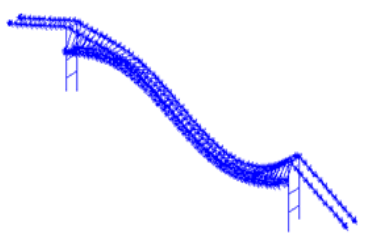

(e) 1st ASVB MG (FEM)

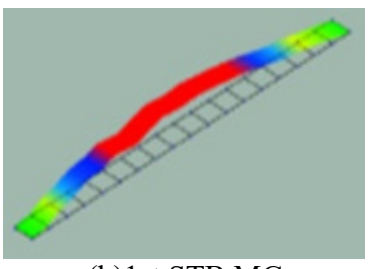

(b)1st STB MG

(measured mode )

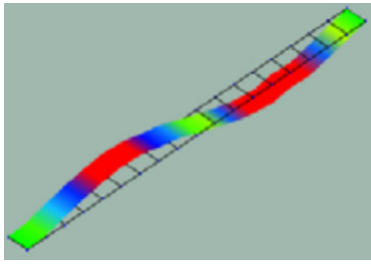

(f)1st ASVB MG

(measured mode)

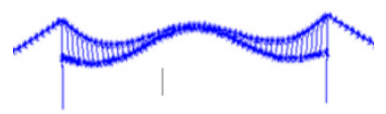

(c)1st SVB MG (FEM)

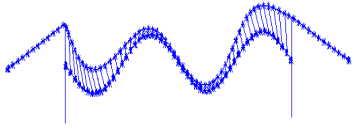

(g2nd ASVB MG (FEM)

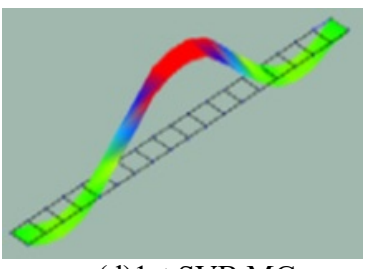

(d)1st SVB MG

(measured mode)

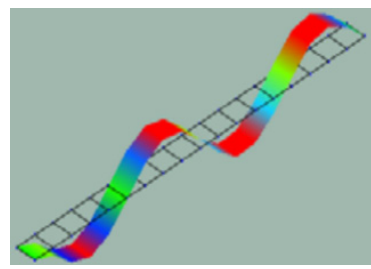

(h)2nd ASVB MG

(measured mode)

Figure 2. Comparison of Measured and Theoretical Model Shapes

From the data in the table and the curve in the figure, it can be seen that the actual measured value is basically the same as the theoretical value. Except for the first two-order error within $10 \%$, the first two-order error may be related to factors such as the sensitivity of the sensor, as can be seen from Figure 3. The theoretical mode is in good agreement with the measured mode. Therefore, the vibration mode, natural vibration frequency, and damping parameters of the background bridge obtained through theoretical analysis can characterize the actual state of the bridge structure.

Table 2 Statistical Table of Bridge dynamic characteristics

\begin{tabular}{|c|c|c|c|c|c|c|}
\hline \multirow{2}{*}{\multicolumn{3}{|c|}{ Serial number Vibration direction vibration mode - }} & \multirow{2}{*}{\multicolumn{2}{|c|}{$\frac{\text { natural vibration frequency } / \mathrm{Hz}}{\text { Theoretical value Measured value }}$}} & \multirow{2}{*}{\multicolumn{2}{|c|}{$\begin{array}{l}\text { error Damping ratio } \\
1 \%\end{array}$}} \\
\hline & & & & & & \\
\hline 1 & Vertical + vertical & 1st LD MG & 0.1261 & 0.15 & 16.00 & 2.45 \\
\hline 2 & Horizontal & 1st STB MG & 0.1338 & 0.16 & 16.20 & 4.87 \\
\hline 3 & \multirow{3}{*}{ Vertical } & 1st ASVB MG & 0.1786 & 0.17 & 5.30 & 2.36 \\
\hline 4 & & 1st SVB MG & 0.2243 & 0.23 & 2.60 & 2.35 \\
\hline 5 & & 2nd ASVB MG & 0.3928 & 0.39 & 0.80 & 1.10 \\
\hline 6 & torsion & 1st ST MG & 0.5331 & 0.56 & 4.80 & 0.99 \\
\hline
\end{tabular}

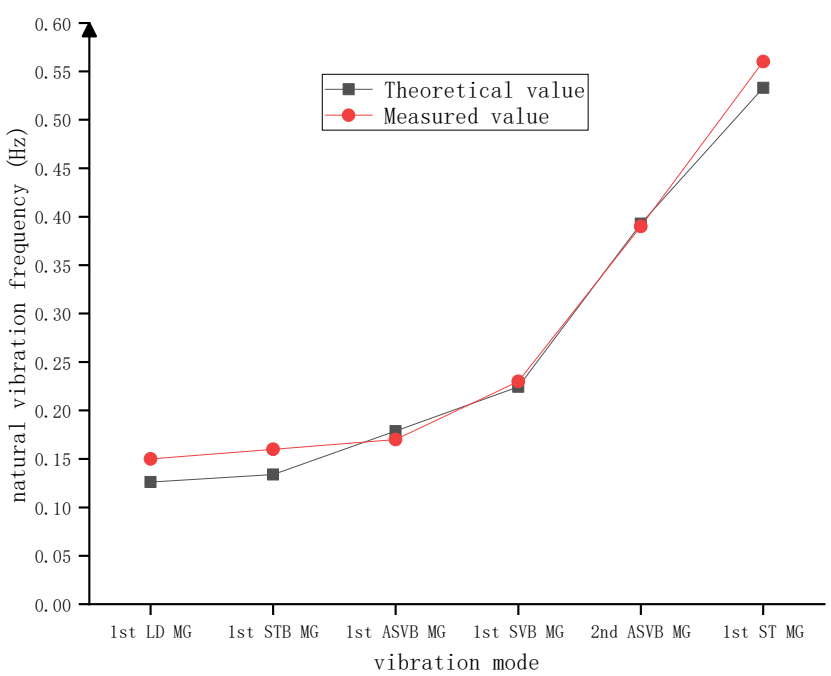

Figure 3. Comparison of Measured and Theoretical Values of Frequency 


\section{Dynamic parameter analysis}

In order to study the influence of different structural parameters of long-span suspension bridges on its dynamic characteristics, three important influencing parameters of the influencing factors of dynamic characteristics are extracted to discuss the influence of dynamic characteristics on the natural vibration frequency of the suspension bridge. It mainly includes: the secondary dead load of the bridge deck system, the bending rigidity of the main tower and the bending rigidity of the stiffening girder.

\subsection{The influence of the secondary dead load of the bridge deck system on the dynamic characteristics}

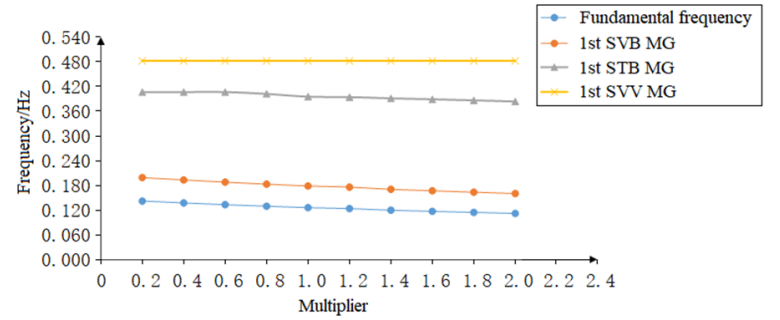

(a)

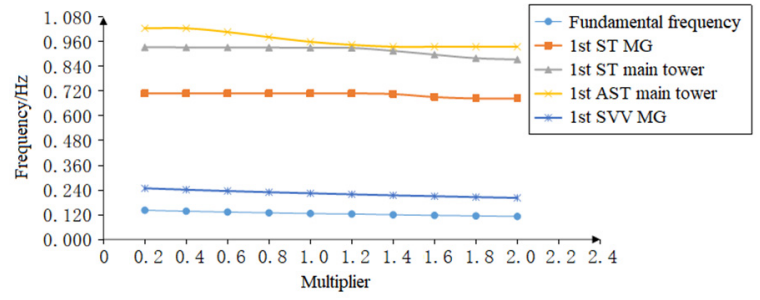

(b)

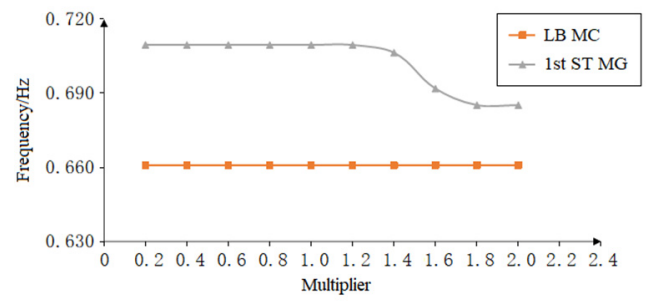

(c)

Figure 4. Change of Frequency with Increase of Secondary Dead Load

When analyzing the dynamic characteristics of a suspension bridge, dead load is a very important factor, which has a greater impact on the vibration of the suspension bridge. The mass of the girder element should not only include its own weight but also the mass of the bridge deck system. Therefore, in the process of analyzing the dynamic characteristics, the influence of the secondary load on the dynamic performance of suspension bridge should also be considered. Assume that $\mathrm{n}$ is the multiple of the increase in the design value of the dead load in the second phase of the background bridge. Then compare and analyze the vibration characteristic values of the suspension bridge, and the analysis results are shown in Figure 4.

It can be seen from Figure 4 that most of the frequency curves with the secondary dead load show a trend of first decreasing and then tending to be stable. The increase of the secondary dead load can reduce the natural frequency of the suspension bridge,

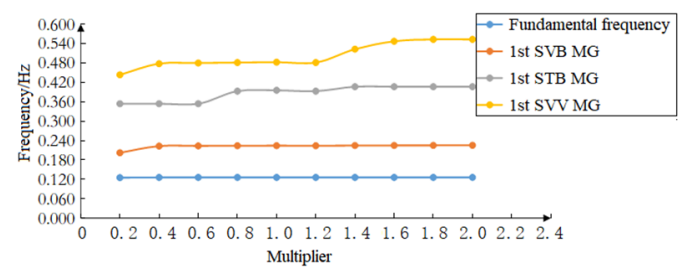

(a) but it is not unlimited to increase the secondary dead load to reduce the frequency.

\subsection{Influence of the stiffness of the main tower on dynamic characteristics}

In order to analyze the influence of the stiffness of the main tower of the suspension bridge on the dynamic characteristics of the suspension bridge, the analysis was carried out by changing the stiffness of the main tower, and the previous method was still adopted on the basis of the original design stiffness. Assuming that $\mathrm{n}$ is a multiple of the increase in the design value of the main tower stiffness, the vibration characteristic value of the suspension bridge is compared and analyzed. The analysis result is shown in Figure 5.

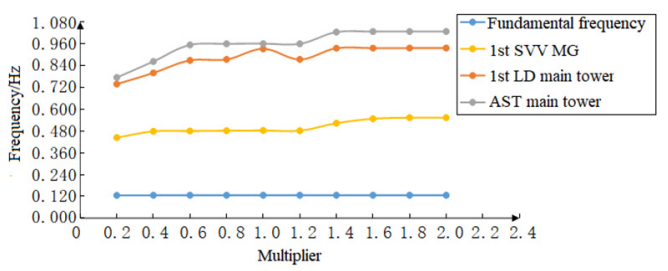

(b) 


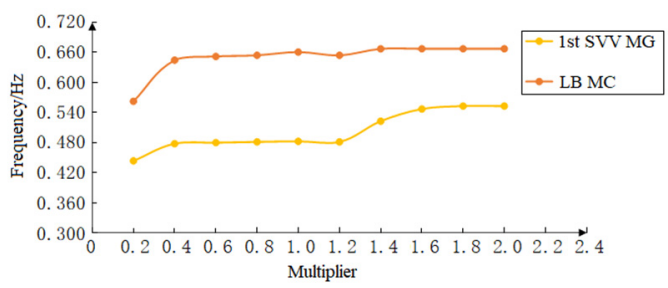

(c)

Figure 5. Change of Frequency with Increase of Stiffness of the Main Tower

It can be seen from Figure 5 that when the stiffness of the main tower is changed, most of the curves of frequency change with the increase in stiffness show an upward trend and the amplitude is relatively large, but the stiffness of the main tower has little effect on the first-order mode shape. Therefore, the stiffness of the

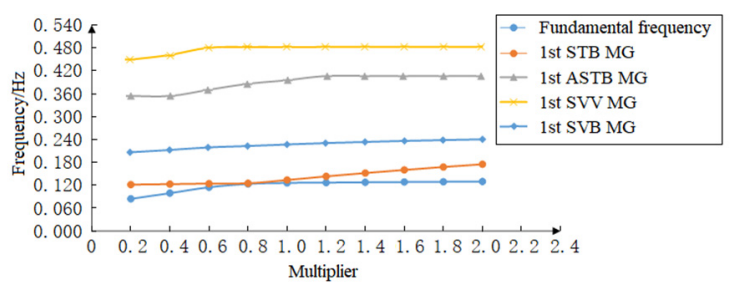

(a) main tower is also a key factor affecting the dynamic characteristics of the suspension bridge.

\subsection{Influence of the stiffness of stiffening girder stiffness on dynamic characteristics}

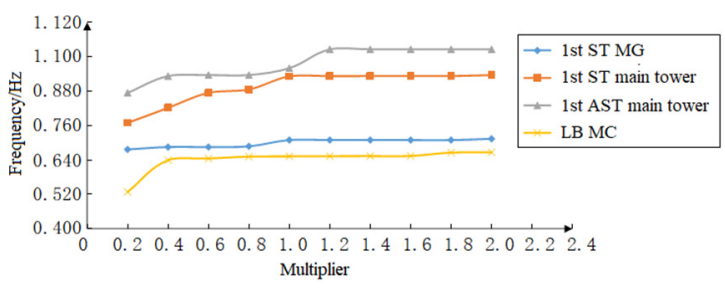

(b)

Figure 6. Change of Frequency with Increase of Stiffness of the Stiffening Girder

The stiffness of the stiffening girder has a great influence on the natural frequency of the suspension bridge as a whole, so it is necessary to analyze the change rule of the frequency caused by the change of the stiffness of the stiffening girder. Assuming that $\mathrm{n}$ is the multiplier that the design value of stiffening girder stiffness increases, the vibration characteristic value of the suspension bridge is compared and analyzed, and the analysis result is shown in Figure 6.

It can be seen from Figure 6 that when the stiffness of the stiffening girder is changed, the change curve of frequency with the increase of stiffness mostly shows an upward trend, and the amplitude is relatively large. If the bending stiffness of the stiffening girder is increased to three times the original, the original vibration mode order of the structure will be changed. Therefore, key considerations should be given in the design calculations.

\subsection{Coupling analysis}

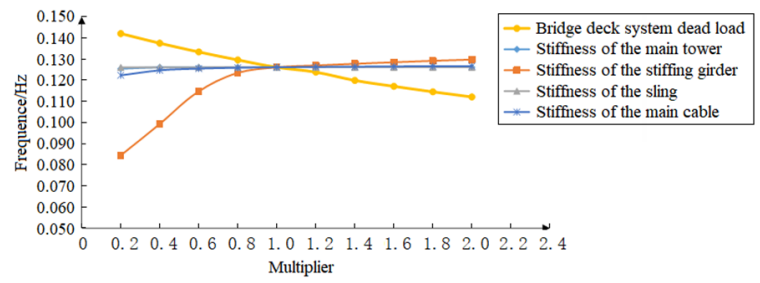

Figure 7. Variation of Fundamental Frequency with Stiffness of Each Component
Using the control variate method, only one of the many variables is changed, and the natural vibration frequency change of the suspension bridge caused by the change of one of the variables is analyzed. The specific results are shown in Figure 7-11.

It can be seen from the changes of the various parameters in Figure 7-11 with the stiffness of each component that most of the frequencies increase with the increase of the stiffness of each component of the suspension bridge, and the most obvious change is the stiffness change of the stiffening girder; with the increase of the dead load of the suspension bridge deck system, it decreases; in the previous changes, the stiffness of the main cable has a greater impact on the frequency, followed by the stiffness of the main tower; the stiffness of the sling has little effect on the vibration frequency of the structure.

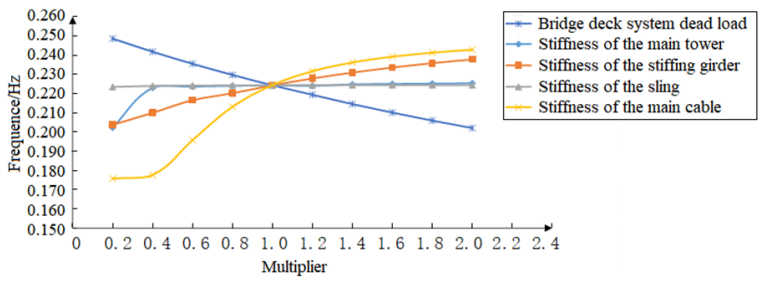

Figure 8. Variation of 1st SVB MG Frequency with Stiffness of Each Component 


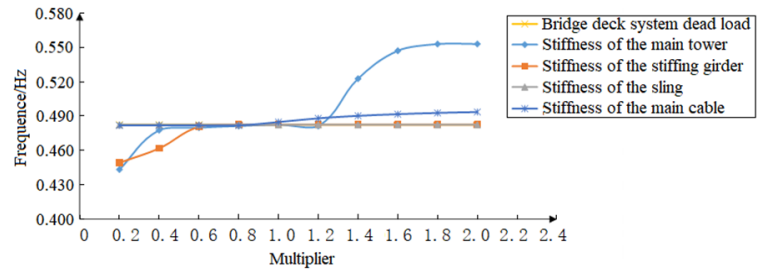

Figure 9. Variation of 1st LD MG Frequency of Main Tower with Stiffness of Each Component

It can be seen that the stiffness of the bridge deck system can always reduce the vibration frequency of the structure; changing the stiffness of the main tower has a greater impact on the 1st LD MG, and the increase in the dead load of the bridge deck system can reduce this stage in the later stage. The frequency of vibration. At the same time, the stiffness of the sling has little effect on the 1st LD MG. The stiffness of stiffening girder also has a certain influence on the 1 st LD MG in the early stage.

\section{Results}

(1) The finite element model of the background bridge was established through the finite element software, the dynamic characteristics of the background bridge were analyzed, and the accuracy of the data obtained by the numerical simulation was verified through experiments. The first-order natural vibration frequency was obtained as $0.1261 \mathrm{~Hz}$, the period is $7.9312 \mathrm{~s}$, the vibration mode is $1^{\text {st }} \mathrm{LD} \mathrm{MG}$ and the theoretical value is consistent with the value of field test.

(2) Through the analysis of its dynamic characteristics, and the first-order natural vibration frequency is lower than other vibration modes' frequency and has a longer period. In the first-order vibration mode, the stiffness change of the stiffening girder has a greater impact on the natural vibration frequency of the suspension bridge; changing the stiffness of the main tower has a small effect on the first-order frequency, so the main tower can choose a more economical size when meeting the requirements of the specification; it is the secondary dead load that can effectively reduce the natural vibration frequency of the suspension bridge, but it is not unlimited.

(3) The increase in the bending stiffness of the stiffening girder will affect the LD, TB, SVB, ASVB, ST and AST of the long-span suspension bridge, especially the influence on the TB MG. Significantly, when the bending stiffness of the stiffening girder is doubled, the first-order lateral natural vibration frequency of the stiffening girder increases by $31 \%$. When the bending stiffness of the stiffening girder is increased to 3 times, the mode shape of the long-span suspension bridge is reordered, which may cause the 1st ASVB MG appears before the 1st SVB MG.

\section{Acknowledgments}

The authors would like to acknowledge the financial support provided by"the National Natural Science Foundation of China (No.51808274)", "China Postdoctoral Science $\quad$ Foundation
(No.2019M653897XB)", "Natural Science Foundation of Gansu Province（No.2017GS10911）.

\section{References}

1. HUA Xu-gang HUANG Zhi-wen CHEN Zhengqing 2019 Multi-model Vertical Vortex-induced Vibration Suspension Bridge and Control Strategy China Journal of Highway and Transport 32(10) 115-124 (In Chinese)

2. XIANG Yi-qiang QIU Zheng HE Bai-da et al 2020 Analytical Approach for the Free Vibration of Accelerated Construction Steel-concrete Composite Small Box Girders with External Prestressed Tendons and Group Studs China Journal of Highway and Transport 33(1) 100-110 (In Chinese)

3. XIA Jin-lin LI Ke GE Yao-jun 2016 Dynamic Characteristics and Flutter Performance of Suspension Bridge with Double Introverted Main Cable Journal of Huazhong University of Science and Technology(Natural Science Edition) 44(6) 91-97 (In Chinese)

4. LI Yong-le XU Xin-yu YAN Nai-jie et al 2015 Comparison of Wind-vehicle-bridge Coupling Vibration Characteristic for Three-line Ywo-tower Suspension Bridge Journal of Traffic and Transportation Engineering 15(6) 17-25 (In Chinese)

5. LIU Jia-bing 2020 Analysis of Global Static And Dynamic Property of Long-span Steel Truss Girder Rail-cum-road Suspension Bridge Bridge Construction 50(4) 23-28 (In Chinese)

6. CHEN Yang REN Dong-hua ZOU Chun-rong Dynamic 2020 Property Analysis and Tests for Main Bridge of Xing Kang bridge on Ya'an-Kang ding expressway World Bridges 48(4) 45-48 (In Chinese)

7. XIAO Hai-zhu ZHANG Xiao-yong XU Gong-yi 2019 Study on Static and Dynamic Property of Main Bridge of Yangsigang Changjiang River Bridge in Wuhan World Bridges 47(6) 70-73 (In Chinese)

8. WANG Hao YANG Min TAO Tianyou et al 2016 Parameter Sensitivity Analysis of Dynamic Characteristics of Long-span Quadruple-tower suspension Bridge Journal of Southeast University(Engilish Edition) 46(3) 559-564 (In Chinese)

9. XU Shuo WAN Yu WU Wen-peng 2020 Research on Dynamic Characteristics and Test of the Large Span Suspension Bridges in Mountain 
Zones with Steel Truss Girders Highway Engineering 45(3) 18-22 (In Chinese)

10. WANG Wen-jun DING Shi-guang BAI Wei-gang et al 2018 Seismic Damage Assessment and Influence Parameter Analysis of Precast Segmental Prestressed Piers China Journal of Highway and Transport 31(12) 258-266 (In Chinese)

11. Xia Zhi-yuan Li Ai-qun Li Jian-hui et al 2016 Sensitivity Analysis on Dynamic Characteristics of Self-anchored Suspension Bridge with Super-wide Girder Journal of Southeast University (Natural Science Edition) 46(2) 360-364 (In Chinese)

12. Tao T Y Wang H Yao C Yet al 2017 Parametric Sensitivity Analysis on the Buffeting Control of a Long-span Triple-tower Suspension Bridge with MTMD Applied Sciences-Basel 7(4) 1-22

13. Nazim N A Aerodynamic 2017 Stability Parameters Optimization and Global Sensitivity Analysis for a Cable Stayed Bridge KSCE Journal of Civil Engineering 21(5) 1866-1881 